\title{
Student Perceptions and learning outcome on Primary Mental Ability-based Pharmacology Learning
}

\author{
Madhav M. Mutalik ${ }^{1}$, Maitreyee M. Mutalik ${ }^{2}$,
}

\begin{abstract}
Objectives: To test the perceptions and learning outcome of undergraduate medical students on primary mental-ability based pharmacology modules at American Institute of Medicine, Seychelles.

Methods: Pharmacology teaching was conducted for 13 weeks to two groups of students in the undergraduate MD program using 2 different methods. Group A $(n=56)$ was taught by the newly designed 9 modules based on Louis Thurstone's concept of primary mental abilities of spatial-visual and numerical abilities, perceptual speed, and inductive reasoning. Group B $(n=50)$ received the conventional teaching with 4 traditional methods. Student perceptions were tested in both groups. Learning outcome was compared by administering a comprehensive pharmacology examination.
\end{abstract}

Results: Group A taught by the newly designed primary mental ability-based modules recorded higher perception scores as compared to Group B taught by traditional methods. The difference was statistically significant on two-sample Kolmogorov-Smirnov Test $(p<0.025)$ as well as Mann-Whitney test $(p<0.025)$. Pharmacology examination yielded higher scores for Group A taught by primary mental ability-based modules, with a statistically significant difference on "Wilcoxon Rank Sum" (Mann-Whitney U test) $(p<0.01)$ and "Unpaired test" $(p=0.0097)$.

Conclusion: Student perceptions and learning outcome was strongly positive for learning modules based on primary mental abilities of spatial-visual and numerical abilities, perceptual speed, and inductive reasoning.

Keywords: Student perceptions, primary mental abilities, learning, medical education, pharmacology

\section{Introduction}

Traditional undergraduate pharmacology curriculum has undergone many changes. The need for change was felt due to ethical issues and lack of animals for experiments, doubts about clinical utility of dispensing pharmacy, and issues relating to integration and application of pharmacology knowledge in clinical setup (Bhavsar, et al., 1999; Gitanjali, 2001; Kaushal, et al., 2007; Mathur, 2004). Deletion of pharmacy and animal experiments

\footnotetext{
${ }^{1}$ MBBS, MD (Pharmacology), MBA

Associate Professor of Pharmacology,

MIMER Medical College, Telegaon-Dabhade, Pune (India) ${ }^{2} M B B S, M D$ (Anatomy), DA, MBA

Assistant Professor, Department of Anatomy,

MIMER Medical College, Tategaon-Dabhade, Pune (India)

Corresponding author:

Dr. MadhavMutalik

MIMER Medical College, Talegaon-Dabhade, Pune (India)
}

was considered and recommended by many educationists (Hariharan, 2004; Rai, 2006). Competency-based, ability-based, and problem-based curricula were developed at many institutes in order to improve learning outcome (Near, et al., 2002; Franson, et al., 2005). Specific ability-based education was implemented in some other programs (Ability based curriculum, 2011).

Traditional medical curriculum is packed with constantly expanding knowledge information and relies heavily on memorization of facts and acquaintance of medical vocabulary (D'Souza, et al., 2008). The present study originated while working with students, understanding their difficulties and ways of learning, curiosity in the learning process, and interest in making their learning an enjoyable process. Learning behavioral science and human resource management further triggered the idea of the present work.

Email:drmadhavmutalik@yahoo.com,

madmutalik@rediffmail.com 
Psychologist and psychometrician Louis Thurstone worked on theories of intelligence and derived seven primary mental abilities possessed by human beings. He found that persons with similar intelligence quotients (IQ scores) may have different profiles of primary mental abilities, and they may learn and understand better if their primary mental abilities are explored (Thurstone, 1938; Cockcroft \& Israel, 2009). Verbal comprehension, verbal fluency, and memory capacity are the abilities explored in traditional curricula (D'Souza, et al., 2008), whereas medical professionals need to constantly use spatialvisual ability, numerical ability, perceptual speed (speed of perception and comparison between different images, numbers, data, pictures, situations), and inductive reasoning (ability to analyze logically and come to conclusion). These abilities are applied during the clinical examination, diagnostic procedures, and correlation of disease process (Sontakki, 2007). Hence, in the present study, 9 teaching modules based on these four primary mental abilities were designed to deliver the pharmacology content.

\section{Methods}

In the present study conducted at the American Institute of Medicine, Seychelles, the pharmacology content was delivered for 13 weeks to two groups of students from undergraduate MD medical program by 2 different methods. Group A $(n=56)$ received the newly designed 9 primary mental abilitybased pharmacology modules, while Group B $(n=50)$ received the conventional pharmacology teaching with 4 traditional learning methods that included didactic lecturing, conventional practical exercises, demonstrations, and tutorials. The design was approved by the Ethical Committee and Curriculum Development Committee of the institute. Written consent was signed by all students.

\section{Assessment of student perception:}

At the end of the $13^{\text {th }}$ week, student perceptions from both groups about the usefulness of each module were recorded on a 5-point scale (1 lowest and 5 highest) (Succar \& Grigg, 2010). The common statement for each module was: "This module was useful to me, to easily, clearly, and effectively understand, and reproduce and analyze the basic pharmacological concept." The student perception scores from both the groups were compared by two-sample KolmogorovSmirnov test and the Mann-Whitney Test.

\section{Preferential scoring on newly designed modules:}

The students from Group A (taught by primary mental ability-based modules) were further requested to choose 3 modules that helped themthe most, on a scale 1-3 (1 highest and 3 lowest) (Nageswari, 2004). This was done to find out their preferences amongst the newly designed modules.

\section{Assessment of learning outcome:}

At the end of a 2-week preparation time, both groups were administered a 100-mark comprehensive pharmacology examination consisting of 100 multiple choice questions with five options for each question with one correct answer. The comparison of marks scored in the two groups was done by "Wilcoxon Rank Sum" (Mann-Whitney U test) as well as "Unpaired $t$ test".

Following is a brief description of the newly designed modules used for Group A. These modules were designed to explore spatialvisual ability, numerical ability, perceptual speed, and inductive reasoning.

\section{Module 1: Mathematical Exercises:}

Simple math calculations needing only concrete operations of addition, subtraction, multiplication, and division were included. Formulae were supplied and calculators were allowed! The content covered various pharmacokinetic parameters.

\section{Module 2: Graphs and Curves:}

Drawing and interpretation of graphs and curves relating to dose-response relationships, antagonism, Gaussian distribution, cardiovascular and autonomic effects of drugs, and mechanism of action of anti-arrhythmic agents were included.

\section{Module 3: Formulations-Images-Pictures:}

Concepts on pharmacological actions, mechanisms of action, drug-receptor interactions, and adverse drug reactions were included.

\section{Module 4: "Self-Talk":}

This module was based on theory of social learning, self-efficacy, and self-regulation by Canadian psychologist, Albert Bandura (Cherry, 2011).The student was given 10 minutes to go through the supplied information, and 5 minutes to prepare their ideas. Then the student was asked to deliver a 3-minute "Self-Talk" on the given data. During the "Self-Talk", the student did not face an audience or teacher. The teacher did not 
interrupt the student during the "Self-Talk". The student talked aloud but as if talking to self. The teacher was out of sight, but was able to hear clearly, and the teacher made notes on the student's performance. After the "Self-Talk", the student was asked to make notes on what she/ he missed. The teacher noted the points covered as well as missed by the student, and summarized the student's performance (Totten, 1991). The concepts covered in this module were rationale for treatment and drug combinations, cases, and laboratory data.

\section{Module 5: Comorbid Conditions:}

The students were facilitated to discuss case examples of comorbid disease conditions and complex drug treatment strategies.

\section{Module 6: Drug Interactions:}

The exercises provided a scope to imagine the possibility, mechanism, and outcome of drugdrug interactions through active learning by project assignments of tables, charts, posters, and pictures.

\section{Module 7: Loud Thinking:}

The basis for this module was "think aloud" strategy (Tinzmann, et al., 1990; Duffin 2009). It included loud pronunciation of difficult drug names and medical terms, "sound-alike" and "spell-alike" drug names, and differentiating between the drugs.
Module 8: Prescriptions and Adverse Drug Reactions:

Exercises included criticism and correction of given prescriptions, justifying or criticizing and commenting on rational and irrational combinations, adverse drug reactions, precautions, and relevant instructions to the patient.

\section{Module 9: Evidence-based Exercises:}

This module changed the usual classroom environment by the use of "home medicinebox contents", "over-the-counter" formulations, visits to pharmacy, prescriptions received by students or their relatives, and experiences of medication use.

\section{Results}

\section{Student perception scores:}

Student perception scores of Group A (primary mental ability-based modules) $(n=56)$ for 9 different modules were in the range of 3.821 to 4.339. Student perception scores of Group B (conventional methodology) $(n=50)$ for 4 traditional teaching methods were in the range of 2.140 to 3.060 . The student perception scores were higher for Group $A$ as compared to Group B, and the difference was statistically significant on two-sample Kolmogorov-Smirnov Test $(p<0.025)$ as well as Mann-Whitney test $(p<0.025)$. Table 1 shows average of student perception scores in Group $A$ and Table 2 shows average of student perception scores in Group B.

Table 1: Average of student perception scores in Group A $(n=56)$ for individual primary-mental ability based modules and the corresponding primary mental ability

\begin{tabular}{cllc}
\hline No & Module & Principle/Learning Ability & Averaged Score \\
\hline 1 & Mathematical Exercises & Numerical ability, perceptual speed & 3.857 \\
2 & Graphs and Curves & $\begin{array}{l}\text { Spatial-visual ability, perceptual speed, } \\
\text { inductive reasoning }\end{array}$ & 3.821 \\
3 & Formulations-Images-Pictures & $\begin{array}{l}\text { Spatial-visual ability, perceptual speed, } \\
\text { inductive reasoning }\end{array}$ & 4.035 \\
4 & Self-Talk & Inductive reasoning, perceptual speed & 4.160 \\
5 & Comorbid Conditions & Inductive reasoning, perceptual speed & 4.125 \\
6 & Drug Interactions & Inductive reasoning, perceptual speed & 4.000 \\
7 & Loud Thinking & Inductive reasoning, perceptual speed & 4.107 \\
8 & Prescriptions-Adverse Drug Reactions & Inductive reasoning, perceptual speed & 4.017 \\
9 & Evidence-based Exercises & Inductive reasoning, perceptual speed & 4.339 \\
\hline
\end{tabular}


Table 2: Average of student perception scores in Group $B(n=50)$ for individual conventional or traditional teaching methods

\begin{tabular}{clc}
\hline No & Module & Averaged Score \\
\hline 1 & Didactic lecturing & 2.140 \\
2 & Conventional practical exercises & 2.300 \\
3 & Demonstrations & 3.060 \\
4 & Tutorials & 2.460 \\
\hline
\end{tabular}

Table 3: Preferential scoring amongst the primary mental ability-based modules

\begin{tabular}{lllccc}
\hline No & \multicolumn{1}{c}{ Type of Exercise } & Preference & $\begin{array}{c}\text { No of students who } \\
\text { particular module } \\
\text { was in the first 3 } \\
\text { preference }\end{array}$ \\
\hline 1 & Mathematical Exercises & {$[1]$} & {$[2]$} & {$[3]$} & 21 \\
\hline 2 & Graphs and Curves & 8 & 4 & 9 & 19 \\
\hline 3 & Formulations-Images-Pictures & 8 & 6 & 5 & 19 \\
\hline 4 & Self-Talk & 7 & 4 & 8 & 25 \\
\hline 5 & Comorbid Conditions & 11 & 11 & 3 & 15 \\
\hline 6 & Drug Interactions & 6 & 5 & 4 & 10 \\
\hline 7 & Loud Thinking & 2 & 5 & 3 & 20 \\
\hline 8 & Prescriptions-Adverse Drug Reactions & 6 & 6 & 8 & 12 \\
\hline 9 & Evidence-based Exercises & 2 & 6 & 4 & 27 \\
\hline
\end{tabular}

\section{Preferential scores:}

Preferential scoring for the newly designed modules used by Group A $(n=56)$ indicated that a large number of students had "Evidence-based Exercises" (27 students), "Self-Talk" (25 students), and "Mathematical Exercises" (21 students) amongst their first three preferences. Table 3 shows preferential scoring amongst the primary mental abilitybased modules.

\section{Learning outcome:}

On the comprehensive pharmacology examination, the mean score was $76 \%$ for Group A $(n=56)$ (newly designed primary mental ability-based modules), and $72.78 \%$ for Group B $(n=50)$ (traditional learning). This difference was statistically significant on "Wilcoxon Rank Sum" (Mann-Whitney U test) $(p<0.01)$ as well as "Unpaired t test" ( $p=$ 0.0097 ). Table 4 shows the percentage of marks for both groups on a comprehensive pharmacology examination. 
Table 4: Percentage of marks (scores) on a comprehensive pharmacology examination

\begin{tabular}{lcc}
\hline $\begin{array}{l}\text { Marks/Score } \\
\text { in Percentage }\end{array}$ & $\begin{array}{c}\text { Group A } \\
\text { (Mental-Ability Based Learning) } \\
(\mathbf{n}=56)\end{array}$ & $\begin{array}{c}\text { Group B } \\
\text { (Traditional Learning) } \\
(\mathbf{n}=50)\end{array}$ \\
\hline$<50$ & 0 & 0 \\
$50-59$ & 0 & 3 \\
$60-69$ & 5 & 7 \\
$70-79$ & 35 & 30 \\
$80-89$ & 15 & 10 \\
90 and above & 1 & 0 \\
\hline Mean & $\mathbf{7 6}$ & $\mathbf{7 2 . 7 8}$ \\
\hline S.D. & $\mathbf{6 . 0 1}$ & $\mathbf{6 . 5 8}$ \\
\hline
\end{tabular}

\section{Discussion}

Traditional curricula rely heavily on verbal comprehension, verbal fluency, and memory capacity. Comparatively less explored primary mental abilities are spatial-visual and numerical abilities, perceptual speed, and inductive reasoning. Moreover, these less explored abilities are remarkably useful during medical practice. Hence, during the present study, a group of students was taught by a newly designed pharmacology learning modules based on these usually less explored abilities. The perception scores in this group were found to be significantly higher as compared to the group taught by conventional methods. The learning outcome on pharmacology examination also was found to be better for the group taught by newly designed primary mental ability-based modules. "I hear and I forget, I see and I remember, I do and I understand" is a famous quote by philosopher Confucius(551-479 B.C.) (vaillancourt, 2009). Spatial-visual abilities, numerical abilities, perceptual speed, and inductive reasoning are the examples of the abilities based on "seeing the actual happening" and "doing actively". These capacities help to build and strengthen the verbal abilities and memory ability (D'souza, et al., 2008).

Out of the 9 primary mental ability-based modules, the module of "Evidence-based Exercises"scored highest in individual as well as on preferential scoring. These exercises included analysis of "home-medicine box" and visits to pharmacy, which took students to real-life situations and produced active learning by a dynamic change in the classroom environment. "Self-Talk" was another preferred module by individual as well as preferential scoring, and it was based on four stages of Albert Bandura's social learning theory (Cherry, 2011). These stages comprise of "Attention" (presentation of concept to the student), "Retention" (allowing time for organizing and building the thought), "Reproduction" (an impromptu "Self-Talk"), and "Motivation" (positive reinforcement by the teacher at the end). This module was perceived by the students as challenging and as an opportunity of self-expression, which probably was reflected by high individual and preferential scores. During the preferential scoring, "Mathematical Exercises" was also a preferred module; this reflected that exploring numerical abilities makes the learning interesting. "Loud Thinking", a module rated fourth on individual and preferential scoring was enjoyed by the students due to the process of loud pronunciation of difficult "tongue-twisting" and "sound-alike" drug names, and this facilitated the active learning process. Other modules including "FormulationsImages-Pictures", "Graphs and Curves", "Comorbid Conditions", and "Drug Interactions" facilitated the use of combinations of the four usually less-explored primary mental abilities.

\section{Conclusions}

The present study designed the new learning modules to explore Louis Thurstone's idea of primary mental abilities in learners. Exploring the inherent primary mental abilities of perceptual speed, inductive reasoning, spatial- 
visual ability, and numerical ability was useful in effective delivery of basic pharmacological concepts. The student perception was positive as seen by their preferences in terms of understanding and implementation of basic concepts. The learning outcomes were positive as seen by the higher scores in comparison with the students who received conventional learning methods. The mental ability-based methods facilitated improved learning environment and positive learning attitude expressed in terms of active learning, enthusiasm, interest, involvement, and interaction. These factors are helpful to strengthen the memory capacity and verbal comprehension.

\section{Authors' Contributions}

Madhav Mutalik and Maitreyee Mutalik designed the study including the learning modules, and organized, supervised, and participated in learning module delivery. Madhav Mutalik and Maitreyee Mutalik designed and conducted the student perception scoring and wrote the paper.

\section{Acknowledgement}

We would like to acknowledge the students who cooperated and participated in the present study.

\section{References}

Ability based curriculum, (2011) [Online]. Available at: www.alverno.edu/for_educators/ability_curricul um.html [Accessed $2 \overline{8}$ February 2011].

Bhavsar, V.H., Vajpeyee, S.K., Joshi, N.J., Mistry, S.D., Kantharia, N.D. \& Sharma A.K. et al., (1999) Training during practical pharmacology sessions for undergraduate medical students: An experience with a Modified Teaching Programme. Indian Journal of Pharmacology, 34, pp.176-86.

Cherry, K. (2011) What is self-efficacy? [Online]. Available at: http://psychology.about.com/od/ theoriesofpersonality/a/self_efficacy.htm [Accessed 18 February 2011].

Cockcroft, K. \& Israel, N. (2009). Intellectual Development Chapter 16. In: Developmental Psychology. Editors: Watts J, Duncan N, Cockcroft K., $2^{\text {nd }}$ Ed. pp. 344-349.

D'Souza, U.J.A., Ali, O. \& Zainal, A.M. (2008) Innovative strategy in learning \& memory memorization made easy! : A preliminary study. South-East Asian Journal of Medical Education, 2, (1), pp.65-69.
Duffin, F. (2009) Think Aloud Strategy. Session 4: Exploring a Variety of Texts Beyond the Text Book. HSTW/MMEW Webinar Series. Southern Regional Educational Board, Atlanta. [Online]. Available at: http://lexingtonhs.org/Session\% 204\%20Handout\%201.pdf [Accessed 25 February 2011].

Franson, K.L., Dubois, E.A., Van Gervan, J.M.A. \& Cohen, A.F. (2005) Using ability-based educational methodologies to integrate pharmacology throughout a medical school curriculum. Chapter 1 In: Provision and assessment of Pharmacology and Pharmacotherapy Education across an integrated medical school curriculum. Leiden University. pp. 22-30 [Online]. Available at: https://open access.leidenuniv.nl/bitstream/1887/12927/4/0 1.pdf [Accessed February 28, 2011]

Gitanjali, B. (2001) Animal experimentation: Time to sing a swan song. Indian Journal of Pharmacology, 33, p.71.

Hariharan, T.S. (2004) Need for changes in the practical pharmacology curriculum of medical undergraduates. Indian Journal of Pharmacology, 36, p.181.

Kaushal, S., Chopra, S.C. \& Arora, S. (2007) Modifications in the undergraduate MBBS pharmacology practical curriculum: The $\mathrm{DMCH}$ model. Indian Journal of Pharmacology, 39, pp. 57-59.

Mathur, V.S. (2004) Towards a more meaningful teaching method of pharmacology. Indian Journal of Pharmacology, 36, pp. 259-61.

Nageswari, K., Malhotra, A., Kapoor, N. \& Kaur, G. (2004) Pedagogical effectiveness of innovative teaching methods initiated at the Department of Physiology Government Medical College Chandigarh. Advances in Physiology Education, 28, pp. 51-58.

Near, J.A., Bosin, T.R. \& Watkins, J.B. (2002) Inclusion of a competency-based curriculum in medical pharmacology. Naunyn-Schmiedeberg's Archives of Pharmacology, 366, 1, pp. 26-29. DOI: $10.2007 / \mathrm{s} 00210-002-0555-9$.

Rai, Jaswant (2006) Recommendations for undergraduate pharmacology practical curriculum. (For attention of $\mathrm{MCl}$ ). JKPractitioner, 13 (3), pp.175-6. 
Sontakki, C. (2007) Human skills and abilities. In: Foundation of human skills. $1^{\text {st }}$ ed. Pune, India: Mehta Publishing House, pp. 24-5.

Succar, T. \& Grigg, J. (2010) A new vision for teaching ophthalmology in the medical curriculum: The Virtual Ophthalmology clinic. In C.H. Steel, M.J. Keppell, P. Gerbic\& S. Housego (Eds.), Curriculum, technology \& transformation for an unknown future. Proceedings ascilite Sydney 2010, pp.944-947. [Online] Available at: http://www.ascilite. org.au/conferences/sydney10/Ascilite\%20confe rence $\% 20$ proceedings $\% 202010 /$ Succar-poster. pdf. [Accessed 27 February 2011].

Thurstone, L. L. (1938) Primary mental abilities. Chicago: University of Chicago Press. [Online]. Available at: http://www.indiana.edu/ intell/ Ithurstone.shtml [Accessed 6 March 2011].
Tinzmann, M. B., Jones, B.F., Fennimore, T.F., Bakker, J., Fine, C. \& Pierce, J. (1990) New learning and thinking curricula require collaboration. In: What is the collaborative classroom? [Online]. Available at: http://www. teachervision.fen.com/skill-builder/problem solving/48546.htmI\#ixzz1FCUY0tKH [Accessed 28 February 2011].

Totten, S., Sills, T., Digby, A. \& Russ, P. (1991) Cooperative learning: A guide to research. New York: Garland. Retrieved from: Hudson, A., (2011) Building Higher Levels of Critical Thinking With Collaborative Solutions. [Online]. Available at: http://ezinearticles.com/?BuildingHigher-Levels-of-Critical-Thinking-With-Collabo rative-Solutions\&id=2343720 [Accessed 28 February 2011].

Vaillancourt, R. (2009) "I hear and I forget, I see and I remember, I do and I understand" Canadian Journal of Hospital Pharmacy, 62 (4), pp. 272-73. 